\title{
Lessons learned from the continuous glucose monitoring metrics in pediatric patients with type 1 diabetes under COVID-19 lockdown
}

\author{
Avivit Brener ${ }^{1,2} @ \cdot$ Kineret Mazor-Aronovitch ${ }^{2,3,4} \cdot$ Marianna Rachmiel $^{2,5} \cdot$ Noa Levek $^{4} \cdot$ Galia Barash $^{2,5}$. \\ Orit Pinhas-Hamiel ${ }^{2,3,4} \cdot$ Yael Lebenthal ${ }^{1,2} \cdot$ Zohar Landau $^{4,6,7}$
}

Received: 14 June 2020 / Accepted: 12 August 2020 / Published online: 7 October 2020

(c) Springer-Verlag Italia S.r.l., part of Springer Nature 2020

\begin{abstract}
Aims Billions of people have been under lockdown in an attempt to prevent COVID-19 spread. Lifestyle changes during lockdown could lead to deterioration of glycemic control in type 1 diabetes (T1D). We aimed to assess the impact of COVID19 lockdown on the glycemic control of pediatric patients with T1D.

Methods This observational real-life study from the AWeSoMe Group assessed continuous glucose monitoring (CGM) metrics of 102 T1D patients (52.9\% males, mean age 11.2 \pm 3.8 years, mean diabetes duration $4.2 \pm 3.8$ years) who used Dexcom G5. The data were accessed without any interface between patients, caregivers, and the diabetes team. Study variables from CGM metrics were: mean glucose level, time-in-range (TIR, 70-180 mg/dL; 3.9-10 mmol/L), hypoglycemia $(<54 \mathrm{mg} / \mathrm{dL}$; $<3 \mathrm{mmol} / \mathrm{L}$ ), hyperglycemia ( $>250 \mathrm{mg} / \mathrm{dL} ;>13.3 \mathrm{mmol} / \mathrm{L}$ ), coefficient of variation $(\mathrm{CV})$, and time CGM active before and during lockdown. Delta-variable $=$ lockdown variable minus before-lockdown variable.

Results The mean TIR was $60.9 \pm 14.3 \%$ before lockdown, with no significant change during lockdown (delta-TIR was $0.9 \pm 7.9 \%)$. TIR during lockdown was significantly correlated with TIR before lockdown $(r=0.855, P<0.001)$. Patients with improved TIR (delta-TIR $>3 \%$ ) were significantly older than patients with stable or worse TIR $(P=0.028)$. Children aged $<10$ years had a significantly higher $\mathrm{CV}$ before lockdown and during lockdown than children aged $\geq 10$ years $(P=0.02$ and $P=0.005$, respectively). Among children aged $<10$ years, a multiple linear regression model revealed associations of age and lower socioeconomic cluster with delta-TIR $(F=4.416, P=0.019)$ and with delta-mean glucose $(F=4.459, P=0.018)$. Conclusions CGM metrics in pediatric patients with T1D were relatively stable during a nationwide lockdown. Intervention plans should focus on younger patients with lower socioeconomic position.
\end{abstract}

Keywords Type 1 diabetes · Children and adolescents · Continuous glucose monitoring (CGM) metrics · Ambulatory glucose profile $\cdot$ COVID-19 lockdown

Managed by Antonio Secchi.

Avivit Brener

Avivit.brener@gmail.com; avivitb@tlvmc.gov.il

1 Pediatric Endocrinology and Diabetes Unit, Dana Dwek Children's Hospital, Tel Aviv Sourasky Medical Center, 6 Weizmann Street, 6423906 Tel Aviv, Israel

2 Sackler Faculty of Medicine, Tel Aviv University, Tel Aviv, Israel

3 Pediatric Endocrine and Diabetes Unit, The Edmond and Lily Safra Children's Hospital, Chaim Sheba Medical Center, Ramat-Gan, Israel
4 National Juvenile Diabetes Center, Maccabi Health Care Services, Ra'anana, Israel

5 Pediatric Endocrinology Unit, Shamir (Assaf Harofeh) Medical Center, Tzrifin, Israel

6 Pediatrics Department, Barzilai Medical Center, Ashkelon, Israel

7 Faculty of Health Sciences, Ben-Gurion University of the Negev, Beer-Sheva, Israel 


\section{Introduction}

On March 11, 2020, the World Health Organization publicly characterized coronavirus disease (COVID-19) as a pandemic. This infectious disease is demonstrating a tremendous impact on morbidity and mortality rates of the entire world population, in an age-stratified manner [1]. Diabetes has been identified as a risk factor for severe COVID-19 in adults [2]. However, children, adolescents, and young adults with type 1 diabetes (T1D) are not considered at increased risk [3]. Nevertheless, severe manifestations, including fatal cases, were reported in children, and the spread of infection is posing a major health threat in all age groups [4].

Like other respiratory viruses, SARS-CoV-2 spreads from one person to another primarily via droplet infection [5]. Due to its highly contagious nature, extreme preventive measures including social distancing are advised [6]. On March 15, 2020, the Israeli government declared a nationwide lockdown, with restriction of non-necessary movement in the public space, and closure of all educational institutions and leisure time activities. The resultant confinement of people to their homes led to lifestyle changes, including in diet, sleep, and physical activity. Such changes have negative implications on metabolic health $[7,8]$.

Particularly in the management of T1D, adherence to the therapeutic regimen can be adversely affected by changes in daily routine $[9,10]$. Moreover, glycemic control is affected by engaging in regular physical activity and psychological well-being [11]. The major focus during the COVID-19 outbreak is the prevention of infection spread, thus neglecting the impact of lockdown on other health aspects. Eating out of boredom, changes in daily routine, physical inactivity, longer screen time, irregular sleep patterns and increased anxiety are all parameters that may worsen glycemic control $[12,13]$. On the other hand, being at home, under parental supervision, could be associated with better meal planning, more accurate carbohydrate counting and timely insulin administration. We assessed the short-term impact of lockdown on the glycemic control of T1D patients according to continuous glucose monitoring (CGM) data that were obtained without any interface between patients, caregivers and health care providers.

\section{Methods}

\section{Study population}

The study population included patients with T1D ages $\leq 18$ years who were managed by the pediatric diabetes teams from the AWeSoMe Study Group (four pediatric diabetes multidisciplinary clinics in Israel: DanaDwek Children's Hospital, Shamir (Assaf Harofeh) Medical Center, Maccabi Health Care Services and Edmond and Lily Safra Children's Hospital) [14]. The collaborating clinics treated 650 children and adolescents with T1D during the study period; approximately one-half of the patients use real-time CGM devices (Dexcom G5, Dexcom G4, or Medtronic Enlite Sensor) or a Flash Glucose Monitor (FreeStyle Libre). Included in this study were patients who use the Dexcom G5 CGM and chose to share their glucose data with the clinic as part of their routine care. Inclusion criteria were diabetes duration of $>6$ months and sufficient data, as evident by CGM active time $\geq 80 \%$ [15]. Patients who received diabetes consultation during the study period were excluded from the analysis.

\section{Study design}

This is an observational real-life multi-center study, based on data retrieved from medical files and CGM data using Dexcom Clarity software. CGM data were retrieved for two 2-week periods: preceding the lockdown (from February 23, 2020 to March 7, 2020) and during the lockdown (from March 25, 2020 to April 7, 2020). Of note, during the period before lockdown, regular lifestyle was maintained since the number of persons with COVID-19 in Israel was limited. The escalation in number of cases, mainly of people arriving from abroad, led the Israeli government to take extreme preventive measures, with a drastic change in policy. The two periods of this study were selected since they did not include holidays; each period reflects a dramatically different reality.

The study was conducted according to the principles of the Declaration of Helsinki. Each center obtained local ethics committee approval.

\section{Outcome measures}

The information retrieved from medical files included: sociodemographic characteristics [age, sex, households (single/two parents)], socioeconomic position by home address [socioeconomic position (SEP) cluster and SEP index] was analyzed based on the Israel Central Bureau of Statistics' Characterization and Classification of Statistical Areas within Municipalities and Local Councils by the Socio-Economic Level of the Population. The SEP index is an adjusted calculation of 14 variables that measure social and economic levels in the domains of demographics, education, standard of living, and employment [16]. Diabetes-related information retrieved from medical files included: diabetes duration, mode of insulin therapy [multiple daily injections (MDI) or continuous subcutaneous 
insulin infusion (CSII)], coexistent morbidity such as autoimmune diseases [thyroid and celiac] and attention deficit hyperactivity disorder (ADHD).

The information retrieved from the ambulatory glucose profile report included: mean glucose levels $(\mathrm{mg} /$ $\mathrm{dL})$, glucose standard deviation $(\mathrm{SD})(\mathrm{mg} / \mathrm{dL})$, estimated HbA1c (\%), coefficient of variation (CV), percent time CGM active, time-in-target range (TIR) $(70-180 \mathrm{mg} /$ $\mathrm{dL} ; 3.9-10 \mathrm{mmol} / \mathrm{L})$, time in hypoglycemia $(<70 \mathrm{mg} /$ $\mathrm{dL} ;<3.9 \mathrm{mmol} / \mathrm{L})$, time in marked hypoglycemia $(<54 \mathrm{mg} / \mathrm{dL} ;<3 \mathrm{mmol} / \mathrm{L})$, time in hyperglycemia $(>180 \mathrm{mg} / \mathrm{dL} ;>10 \mathrm{mmol} / \mathrm{L})$ and time in severe hyperglycemia ( $>250 \mathrm{mg} / \mathrm{dL} ;>13.3 \mathrm{mmol} / \mathrm{L}$ ). These definitions were according to the international consensus on CGM interpretation [17]. Differences in variables between the period during lockdown and the preceding period were calculated for each patient and are presented as delta-variable (e.g., delta-TIR = TIR during lockdown minus TIR before lockdown).

We stratified the study population to 3 groups according to delta-TIR: improved TIR (delta-TIR $>3 \%$ ), stable TIR $(-3 \% \leq$ delta-TIR $\leq 3 \%)$ and worse TIR (deltaTIR $<-3 \%)$. This stratification was based on charts that translate a change in TIR to a clinically significant change in HbA1c $[18,19]$. Although the difference in TIR is a useful research tool for comparative analysis, consensus regarding a clinically significant difference is lacking [15]. Data were also analyzed by age, $<10$ years (children) and $\geq 10$ years (adolescents), according to the WHO definition of age of adolescence. In young children, T1D management relies solely on caregivers. However, parental involvement in diabetes care declines with age, as patients become more independent during adolescence [20,21].

\section{Statistical analysis}

The data were analyzed using Statistical Package for the Social Sciences software version 25 (SPSS Inc., Chicago, IL, USA). All the statistical tests were two-sided. The data are expressed as means \pm SD. The Mann-Whitney test or the Kruskal-Wallis test was used for comparing ordered or quantitative variables, as appropriate. The $\chi^{2}$ test (or Fisher's exact test for small count tables) was used to compare groups in categorical variables. Pearson's correlation coefficient statistical tests were applied to examine the correlation between two continuous data groups. The paired t-test was used for comparing the means of variables in the two time points in each age group. A multivariate analysis for the relation between age and dependent variables was performed as follows: delta-variables were entered as dependent variables, and age and SEP cluster as the independent variables.

\section{Results}

The mean age of the pediatric patients treated by the collaborating clinics during the study period was $10.9 \pm 3.9$ years, mean age at T1D diagnosis was $7.9 \pm 3.6$ years, the mean diabetes duration $2.9 \pm 2.6$ years, mean SEP cluster $7.2 \pm 2.0$ and mean SEP index $1.088 \pm 1.00$. Comparative analysis between patients included in the study and those not included revealed no significant differences between the two groups in current age, age at T1D onset, diabetes duration and SEP (cluster and index).

The study cohort comprised 102 patients $(52.9 \%$ males), mean age $11.2 \pm 3.8$ years (range $3.2-18.0$ years). The mean age at T1D diagnosis was $7.0 \pm 4.2$ years and the mean diabetes duration $4.2 \pm 3.8$ years. Before lockdown, the mean glucose level was $163.5 \pm 24.2 \mathrm{mg} / \mathrm{dL}$, glucose SD was $63.7 \pm 14.5 \mathrm{mg} / \mathrm{dL}$; the estimated HbA1c $7.3 \pm 0.8 \%(56.3 \pm 8.7 \mathrm{mmol} / \mathrm{mol})$, TIR: $60.9 \pm 14.3 \%$, time $<54 \mathrm{mg} / \mathrm{dL}: 1.2 \pm 1.4 \%$, time $<70 \mathrm{mg} / \mathrm{dL}: 3.9 \pm 3.3 \%$, time $>180 \mathrm{mg} / \mathrm{dL}: 34.1 \pm 16.1 \%$, time $>250 \mathrm{mg} / \mathrm{dL}$ : $11.3 \pm 9.3 \%, \mathrm{CV}: 38.8 \pm 6.0 \%$ and time CGM active: $93.1 \pm 7.8 \%$. The mean TIR during the lockdown was $61.8 \pm 15.7 \%$; delta-TIR was $0.9 \pm 7.9 \%$. TIR improved for $39(38 \%)$ of the patients, remained stable for $32(31 \%)$ and worsened for 31 (30\%).

Patients with improved TIR (delta-TIR $>3 \%$ ) were significantly older than patients with stable TIR and worse TIR (delta-TIR $<-3 \%$ ) (Table 1). Sociodemographic characteristics (sex and socioeconomic variables), prevalence of comorbid conditions and CGM metrics did not differ significantly between these groups.

Before lockdown, glucose SD did not differ between adolescents ( $\geq 10$ years) and children $(<10$ years) $(P=0.269)$ (Table 2). During lockdown, glucose SD was significantly lower in the older than the younger group $(P=0.034)$ (Table 2). CV was significantly higher among the younger than the older children, before lockdown and during lockdown ( $P=0.02$ and $P=0.005$, respectively). The other CGM metrics, including delta-TIR, did not differ between the age groups either before or during lockdown.

CGM metrics before and during lockdown did not differ between the 74 patients treated by CSII and the 28 patients treated by MDI. Significant differences in age, sex, mode of the therapy and CGM metrics were not observed between the 18 patients with lower SEP cluster (score 3 to 6 ) and the 84 patients with higher SEP cluster (score 7 to 9 ).

Univariate analysis revealed an association of TIR before lockdown with TIR during lockdown $(r=0.855$, $P<0.001)$, as presented in Fig. 1. Neither mean glucose levels nor TIR before lockdown was associated with 
Table 1 Sociodemographic and diabetes-related characteristics of the study cohort stratified by change in time-in-range (TIR)

\begin{tabular}{|c|c|c|c|c|}
\hline & Delta-TIR $<-3 \%$ & $-3 \% \leq$ delta-TIR $\leq 3 \%$ & Delta-TIR $>3 \%$ & $P$ \\
\hline Mean delta-TIR, $\%$ & $-8.2 \pm 3.7$ & $0.3 \pm 1.9$ & $8.7 \pm 4.9$ & $<0.001$ \\
\hline Number & 31 & 32 & 39 & \\
\hline Sex, boys & $18(58.1)$ & $17(53.1)$ & $19(48.7)$ & 0.739 \\
\hline Age, years & $10.6 \pm 4.2$ & $10.3 \pm 3.4$ & $12.5 \pm 3.5$ & 0.028 \\
\hline \multicolumn{5}{|c|}{ Diabetes-related characteristics } \\
\hline Age at T1D diagnosis, years & $6.9 \pm 3.9$ & $6.5 \pm 3.9$ & $7.6 \pm 4.6$ & 0.517 \\
\hline Diabetes duration, years & $3.7 \pm 3.6$ & $3.8 \pm 3.1$ & $4.9 \pm 4.4$ & 0.363 \\
\hline Insulin pump therapy & $18(58.1)$ & $25(78.1)$ & $30(76.9)$ & 0.135 \\
\hline \multicolumn{5}{|l|}{ CGM metrics before lockdown } \\
\hline Mean glucose, mg/dL & $160.2 \pm 23.9$ & $170.6 \pm 26.5$ & $160.3 \pm 21.8$ & 0.134 \\
\hline Glucose SD, mg/dL & $64.0 \pm 16.0$ & $64.3 \pm 16.3$ & $62.9 \pm 11.8$ & 0.908 \\
\hline Estimated $\mathrm{HbA} 1 \mathrm{c}, \%$ & $7.2 \pm 0.8$ & $7.6 \pm 0.9$ & $7.2 \pm 0.8$ & 0.140 \\
\hline Estimated $\mathrm{HbA} 1 \mathrm{c}, \mathrm{mmol} / \mathrm{mol}$ & $55.2 \pm 8.7$ & $59.6 \pm 9.7$ & $55.2 \pm 8.7$ & 0.140 \\
\hline Time $<54$ mg/dL, $\%$ & $1.4 \pm 1.4$ & $1.1 \pm 1.7$ & $1.3 \pm 1.1$ & 0.705 \\
\hline Time $<70 \mathrm{mg} / \mathrm{dL}, \%$ & $4.8 \pm 3.7$ & $3.0 \pm 2.9$ & $4.3 \pm 3.1$ & 0.066 \\
\hline Time-in-range, $\%$ & $62.8 \pm 14.0$ & $58.1 \pm 16.4$ & $61.7 \pm 12.4$ & 0.381 \\
\hline Time $>180 \mathrm{mg} / \mathrm{dL}, \%$ & $32.4 \pm 14.6$ & $38.7 \pm 16.7$ & $33.0 \pm 12.4$ & 0.153 \\
\hline Time $>250 \mathrm{mg} / \mathrm{dL}, \%$ & $11.4 \pm 8.8$ & $13.0 \pm 11.5$ & $9.8 \pm 7.5$ & 0.351 \\
\hline Coefficient of Variation, $\%$ & $39.7 \pm 7.1$ & $37.4 \pm 5.6$ & $39.2 \pm 5.3$ & 0.281 \\
\hline \% Time CGM Active & $94.0 \pm 5.0$ & $94.4 \pm 8.3$ & $91.3 \pm 9.0$ & 0.197 \\
\hline \multicolumn{5}{|l|}{ Socioeconomic position (SEP) } \\
\hline SEP cluster & $7.6 \pm 1.6$ & $7.4 \pm 1.5$ & $7.7 \pm 1.5$ & 0.688 \\
\hline SEP index & $1.146 \pm 0.771$ & $1.115 \pm 0.746$ & $1.256 \pm 0.735$ & 0.706 \\
\hline Two-parent household & $26(83.9)$ & $27(84.4)$ & $32(82.1)$ & 0.962 \\
\hline Number of children & $2.7(0.9)$ & $2.7(1.1)$ & $2.4(1.0)$ & 0.393 \\
\hline \multicolumn{5}{|l|}{ Comorbid conditions } \\
\hline Celiac disease & $1(3.2)$ & $4(12.5)$ & $4(10.3)$ & 0.398 \\
\hline Hashimoto thyroiditis & $1(3.2)$ & $2(6.3)$ & $0(0)$ & 0.573 \\
\hline ADHD & $5(16.1)$ & $2(6.3)$ & $2(5.1)$ & 0.225 \\
\hline
\end{tabular}

Data are presented as mean \pm standard deviation and number (percent). Delta time-in-range (TIR) was calculated as follows: TIR during lockdown minus TIR before lockdown

The socioeconomic position (SEP) by home address was analyzed based on the Israel Central Bureau of Statistics' Characterization and Classification of Statistical Areas within Municipalities and Local Councils by the Socio-Economic Level of the Population 2015. The SEP cluster classifies neighborhoods and localities into clusters, with 1 being the lowest rating and 10 the highest. The SEP index is an adjusted calculation of 14 variables that measure social and economic levels in four domains: demographics, education, standard of living, and employment. Bold indicates significance. ADHD Attention-deficit/hyperactivity disorder; CGM Continuous Glucose Monitoring
delta-TIR $(r=-0.061, P=0.541$ and $r=0.03, P=0.726$, respectively). In the $<10$ year age group, age was associated with both delta-CV and delta-time $<54 \mathrm{mg} / \mathrm{dl}$ ( $r=0.359, P=0.021$ and $r=0.310, P=0.049$, respectively); and SEP cluster was inversely associated with delta-mean glucose $(r=-0.311, P=0.047)$. Also in the younger age group, a multiple linear regression model revealed associations of age and lower SEP cluster with delta-TIR $(F=4.416, P=0.019)$ and with delta-mean glucose $(F=4.459, P=0.018)$. No significant correlations were found between the variables in the adolescents age group.

\section{Discussion}

This study demonstrated that children and adolescents with T1D maintained similar CGM metrics during a nationwide lockdown due to the COVID-19 pandemic. Children younger than 10 years had higher glucose SD and $\mathrm{CV}$, which are both markers of glucose variability, as compared to adolescents. For adolescents, markers of variability improved during lockdown, while in the younger age group, they remained stable. In younger children, age and lower SEP were associated with deterioration in glycemic control. 
Table 2 Continuous glucose monitoring (CGM) metrics of a cohort with type 1 diabetes before and during a nationwide lockdown stratified by age-groups

\begin{tabular}{|c|c|c|c|c|c|c|c|c|}
\hline \multirow[t]{3}{*}{ Sex, boys, number (\%) } & \multicolumn{2}{|c|}{ Children age $<10$ years $n=41$} & \multirow[b]{3}{*}{$P^{l}$} & \multicolumn{2}{|c|}{ Adolescents age $\geq 10$ years $n=61$} & \multirow[b]{3}{*}{$P^{2}$} & \multirow{3}{*}{$\begin{array}{l}0.601 \\
P^{3}\end{array}$} & \multirow[b]{3}{*}{$P^{4}$} \\
\hline & \multicolumn{2}{|l|}{$23(56.1)$} & & \multicolumn{2}{|l|}{$31(50.8)$} & & & \\
\hline & Before lockdown & During lockdown & & Before lockdown & During lockdown & & & \\
\hline Glucose, mg/dL & $161.2(23.5)$ & $161.2(24.9)$ & 0.965 & $165.0(24.7)$ & $161.7(25.3)$ & 0.116 & 0.439 & 0.922 \\
\hline Glucose SD, mg/dL & $65.6(15.1)$ & $63.1(14.0)$ & 0.076 & $62.4(14.0)$ & $54.4(12.4)$ & $<0.001$ & 0.269 & $\mathbf{0 . 0 3 4}$ \\
\hline$<54 \mathrm{mg} / \mathrm{dL}, \%$ & $1.5(1.7)$ & $1.3(1.7)$ & 0.253 & $1.1(1.1)$ & $1.0(1.5)$ & 0.944 & 0.152 & 0.350 \\
\hline$<70 \mathrm{mg} / \mathrm{dL}, \%$ & $4.7(3.4)$ & $4.4(3.5)$ & 0.535 & $3.6(3.2)$ & $3.5(3.0)$ & 0.835 & 0.122 & 0.177 \\
\hline Time-in-range, $\%$ & $61.5(14.2)$ & $61.4(15.4)$ & 0.944 & $60.5(14.4)$ & $62.1(16.0)$ & 0.126 & 0.730 & 0.826 \\
\hline$>180 \mathrm{mg} / \mathrm{dL}, \%$ & $32.8(14.1)$ & $33.6(15.5)$ & 0.567 & $35.8(15.0)$ & $34.4(16.6)$ & 0.248 & 0.323 & 0.804 \\
\hline$>250 \mathrm{mg} / \mathrm{dL}, \%$ & $10.7(8.8)$ & $10.6(9.0)$ & 0.959 & $11.7(9.6)$ & $9.7(8.8)$ & 0.009 & 0.595 & 0.617 \\
\hline Coefficient of Variation, $\%$ & $40.5(6.4)$ & $39.1(5.4)$ & 0.041 & $37.7(5.5)$ & $35.9(5.6)$ & 0.009 & 0.020 & 0.005 \\
\hline \% Time CGM Active & $93.9(6.6)$ & $93.8(5.9)$ & 0.813 & $92.6(8.6)$ & $93.0(7.2)$ & 0.691 & 0.415 & 0.556 \\
\hline
\end{tabular}

Data are presented as mean (standard deviation) unless otherwise specified

$P^{1}$ compares values of the CGM parameter before and during the lockdown in children; $P^{2}$ compares values of the CGM parameter before and during the lockdown in the adolescents age group; $P^{3}$ compares values of the CGM parameter before the lockdown between the age groups; $P^{4}$ compares values of the parameter during the lockdown between the age groups. Bold indicates significance. $n$ number, $S D$ standard deviation, $\%$ percent, $C G M$ continuous Glucose Monitoring

Fig. 1 The association between time-in-range (TIR) before and during lockdown. A significant positive correlation was observed between TIR before lockdown and TIR during lockdown $(r=0.855, P<0.001)$

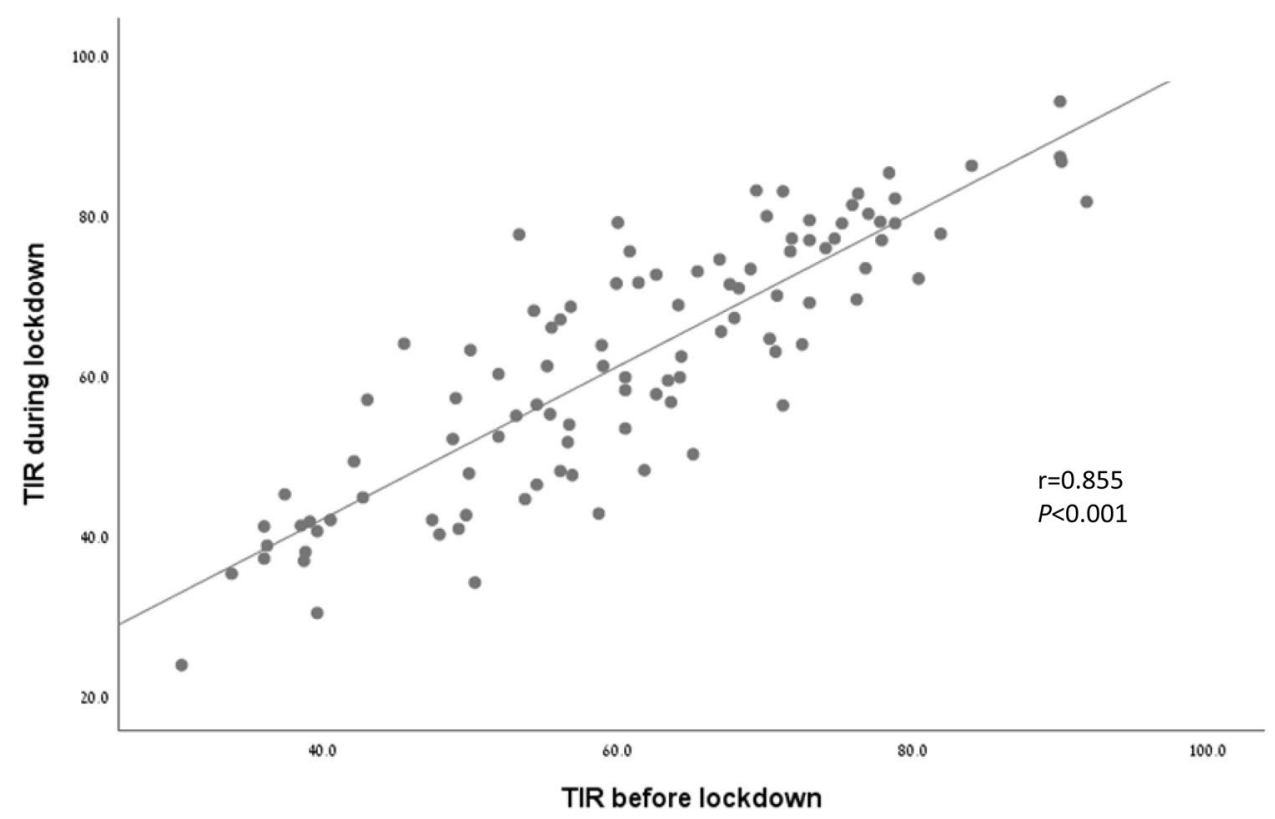

The lockdown has tremendous effects on lifestyle that could potentially cause health-related problems, especially in children and adolescents with T1D. The consumption of ultra-processed and calorie-dense comfort foods, reduced opportunities for physical activity, and extended sedentary activities and screen time could contribute to impaired metabolic health [22, 23]. The notion that diabetes is a risk factor for severe COVID-19 may raise anxiety among caregivers of children with T1D, and prompt them to strictly enforce the recommendation of homestay. Therefore, routine visits in our clinics have declined dramatically, and our patients are not offered the usual standards of care. This has been described in other geographic regions [24].

A recently published model of adults with diabetes predicted deterioration of glycemic control and increased rates of diabetes-related complications during a nationwide lockdown [25]. In contradistinction, recent studies have reported that glycemic control did not deteriorate in adults $[26,27]$ or in children [28] during lockdown. The stable or even improved TIR during lockdown in more than two thirds $(66.9 \%)$ of our cohort add to the cumulative data. This could be attributed to a good adaptation to the changing 
reality, facilitated by CGM usage [29]. The strong association between before- and during-lockdown TIR suggests that patients tended to maintain their glycemic balance despite the dramatic change in daily routine.

We found that glucose variability was more pronounced in younger ( $<10$ years) than older children, before and during lockdown. While adolescents experienced improvement in variability during lockdown, the younger age group maintained similar values as before lockdown. Age was associated with worsened glycemic control during lockdown, as expressed by increased glucose variability, in the age $<10$ years group. Age is known to affect diabetes management. Toddlers are managed by parents and adolescents can manage themselves, children between these age groups vary in their executive function abilities and their nutrition choices [30, 31]. In a time of crisis, like lockdown, behavioral problems may become more prominent.

We also found that among the younger children, lower SEP adversely affected glycemic control, as evidenced by higher mean glucose levels. SEP is a major determinant of health conditions [32]. The COVID-19 pandemic has led to an economic crisis, characterized by increasing rates of unemployment and financial insecurity. The first to suffer are people with lower SEP, for whom financial stability was already difficult [33]. Health care systems should take these findings into consideration in planning contemporary health care strategies.

Our study is not without limitations. Since only patients using CGM were included and only short-term data on lockdown are presented, the results may not reflect the glycemic control of individuals with T1D not using CGM. One strength of this multi-center, observational study is the uniformity of data obtained from a single type of CGM. In addition, this study mirrors a real-life scenario without any medical intervention including dose titrations. This enabled drawing conclusions on patients' management in times of limited access to medical services.

\section{Conclusions}

In summary, we found that glycemic control during lockdown due to COVID-19 remained relatively stable among children and adolescents with T1D. This is reassuring since deterioration of diabetes control has short- and long-term health implications. Future studies are warranted to explore long-term effects of lockdown on glycemic and metabolic outcomes, and to evaluate possible interventions such as telehealth services.

Acknowledgements We wish to thank Cindy Cohen for her editorial assistance.
Author contributions $\mathrm{AB}$ made substantial contributions to the conception and design of the study, acquisition, analysis, and interpretation of data and drafting the initial manuscript. KM-A, NL, GB contributed to the data used in this study, contributed to the discussion and reviewed and edited the manuscript. MR, OP-H and YL made substantial contributions to the conception and design of the study, the interpretation of data and the discussion, and reviewed and edited the manuscript for important intellectual content. ZL made substantial contributions to the conception and design of the study, the interpretation of data, drafting and revising it critically for important intellectual content. All authors gave final approval of the version to be published. $\mathrm{AB}$ is the guarantor of this work, and as such, had full access to all the data in the study and takes responsibility for the integrity of the data and the accuracy of the data analysis.

Funding No funding.

Data availability The data used to support the findings of this study are available from the corresponding author upon request.

\section{Compliance with ethical standards}

Conflict of interest The Authors declare that there is no conflict of interest.

Ethical approval Each center obtained local ethics committee approval. The study was conducted according to the principles of the Declaration of Helsinki and the data were handled according to GCP.

Informed consent Informed consent by the subjects was waived since the data were retrieved from the medical records with no patient contact.

\section{References}

1. Banerjee A, Pasea L, Harris S et al (2020) Estimating excess 1-year mortality associated with the COVID-19 pandemic according to underlying conditions and age: a population-based cohort study. Lancet 395(10238):1715-1725. https://doi.org/10.1016/ S0140-6736(20)30854-0

2. Huang C, Wang Y, Li X et al (2020) Clinical features of patients infected with 2019 novel coronavirus in Wuhan, China. Lancet 395(10223):497-506. https://doi.org/10.1016/S0140 $-6736(20) 30183-5$

3. Coronavirus infection (COVID-19)—II ISPAD Summary 2020. https://www.ispad.org/page/CoronavirusinfectionCOVID-19IIISPADSummary

4. Pavone P, Ceccarelli M, Taibi R, La Rocca G, Nunnari G (2020) Outbreak of COVID-19 infection in children: fear and serenity. Eur Rev Med Pharmacol Sci 24(8):4572-4575. https://doi. org/10.26355/eurrev_202004_21043

5. Li Q, Guan X, Wu P et al (2020) Early transmission dynamics in Wuhan, China, of novel coronavirus-infected pneumonia. N Engl J Med 382(13):1199-1207. https://doi.org/10.1056/NEJMoa2001 316

6. Puig-Domingo M, Marazuela M, Giustina A (2020) COVID-19 and endocrine diseases. A statement from the European Society of Endocrinology. Endocrine 68(1):2-5. https://doi.org/10.1007/ s12020-020-02294-5

7. Martinez-Ferran M, de la Guía-Galipienso F, Sanchis-Gomar F, Pareja-Galeano H (2020) Metabolic impacts of confinement during the COVID-19 pandemic due to modified diet and physical 
activity habits. Nutrients 12(6):E1549. https://doi.org/10.3390/ nu12061549

8. Wang G, Zhang Y, Zhao J, Zhang J, Jiang F (2020) Mitigate the effects of home confinement on children during the COVID-19 outbreak. Lancet 395(10228):945-947. https://doi.org/10.1016/ S0140-6736(20)30547-X

9. McDonough RJ, Clements MA, DeLurgio SA, Patton SR (2017) Sleep duration and its impact on adherence in adolescents with type 1 diabetes mellitus. Pediatr Diabetes 18(4):262-270. https:// doi.org/10.1111/pedi.12381

10. Goethals ER, de Wit M, Van Broeck N et al (2018) Child and parental executive functioning in type 1 diabetes: their unique and interactive role toward treatment adherence and glycemic control. Pediatr Diabetes 19(3):520-526. https://doi.org/10.1111/ pedi. 12552

11. Klaprat NMD, Askin N, MacIntosh A et al (2020) Filling gaps in type 1 diabetes and exercise research: a scoping review and priority-setting project. BMJ Open Diabetes Res Care 8(1):e001023. https://doi.org/10.1136/bmjdrc-2019-001023

12. MacMillan F, Kirk A, Mutrie N, Matthews L, Robertson K, Saunders DH (2014) A systematic review of physical activity and sedentary behavior intervention studies in youth with type 1 diabetes: study characteristics, intervention design, and efficacy. Pediatr Diabetes 15(3):175-189. https://doi.org/10.1111/pedi.12060

13. Tornese G, Ceconi V, Monasta L, Carletti C, Faleschini E, Barbi E (2020) Glycemic control in type 1 diabetes mellitus during COVID-19 quarantine and the role of in-home physical activity. Diabetes Technol Ther 22(6):462-467. https://doi.org/10.1089/ dia.2020.0169

14. Landau Z, Abiri S, Gruber $\mathrm{N}$ et al (2018) Use of flash glucosesensing technology (FreeStyle Libre) in youth with type 1 diabetes: AWeSoMe study group real-life observational experience. Acta Diabetol 55(12):1303-1310. https://doi.org/10.1007/s0059 2-018-1218-8

15. Danne T, Nimri R, Battelino $T$ et al (2017) International consensus on use of continuous glucose monitoring. Diabetes Care 40(12):1631-1640. https://doi.org/10.2337/dc17-1600

16. Israel Central Bureau of Statistics (CBS) (2019) Characterization and classification of geographical units by the socio-economic level of the population, 2015; https://www.cbs.gov.il/he/publicatio ns/DocLib/2019/1765_socio_economic_2015/e_print.pdf

17. Battelino T, Danne T, Bergenstal RM et al (2019) Clinical targets for continuous glucose monitoring data interpretation: recommendations from the international consensus on time in range. Diabetes Care 42(8):1593-1603. https://doi.org/10.2337/dci19 $-0028$

18. Irace C, Cutruzzolà A, Nuzzi A et al (2020) Clinical use of a 180day implantable glucose sensor improves glycated haemoglobin and time in range in patients with type 1 diabetes. Diabetes Obes Metab. https://doi.org/10.1111/dom.13993

19. Beck RW, Bergenstal RM, Cheng P et al (2019) The relationships between time in range, hyperglycemia metrics, and HbA1c. J Diabetes Sci Technol 13(4):614-626. https://doi.org/10.1177/19322 96818822496

20. Pierce JS, Kozikowski C, Lee JM, Wysocki T (2017) Type 1 diabetes in very young children: a model of parent and child influences on management and outcomes. Pediatr Diabetes 18(1):1725. https://doi.org/10.1111/pedi.12351
21. Markowitz JT, Garvey KC, Laffel LM (2015) Developmental changes in the roles of patients and families in type 1 diabetes management. Curr Diabetes Rev 11(4):231-238. https://doi. org/10.2174/1573399811666150421114146

22. Rundle AG, Park Y, Herbstman JB, Kinsey EW, Wang YC (2020) COVID-19 related school closings and risk of weight gain among children. Obesity 28(6):1008-1009. https://doi.org/10.1002/ oby. 22813

23. Lippi G, Henry BM, Bovo C, Sanchis-Gomar F (2020) Health risks and potential remedies during prolonged lockdowns for coronavirus disease 2019 (COVID-19). Diagnosis (Berl) 7(2):85-90. https://doi.org/10.1515/dx-2020-0041

24. Lazzerini M, Barbi E, Apicella A et al (2020) Delayed access or provision of care in Italy resulting from fear of COVID-19. Lancet Child Adolesc Heal 4(5):e10-e11. https://doi.org/10.1016/S2352 $-4642(20) 30108-5$

25. Ghosal S, Sinha B, Majumder M, Misra A (2020) Estimation of effects of nationwide lockdown for containing coronavirus infection on worsening of glycosylated haemoglobin and increase in diabetes-related complications: a simulation model using multivariate regression analysis. Diabetes Metab Syndr 14(4):319-323. https://doi.org/10.1016/j.dsx.2020.03.014

26. Beato-Víbora PI (2020) No deleterious effect of lockdown due to COVID-19 pandemic on glycaemic control, measured by glucose monitoring, in adults with type 1 diabetes. Diabetes Technol Ther. https://doi.org/10.1089/dia.2020.0184

27. Bonora BM, Boscari F, Avogaro A, Bruttomesso D, Fadini GP (2020) Glycaemic control among people with type 1 diabetes during lockdown for the SARS-CoV-2 outbreak in Italy. Diabetes Ther 11(6):1-11. https://doi.org/10.1007/s13300-020-00829-7

28. Schiaffini R, Barbetti F, Rapini N et al (2020) School and preschool children with type 1 diabetes during covid-19 quarantine: the synergic effect of parental care and technology. Diabetes Res Clin Pract. https://doi.org/10.1016/j.diabres.2020.108302

29. Cherubini V, Bonfanti R, Casertano A et al (2020) Time in range in children with type 1 diabetes using treatment strategies based on nonautomated insulin delivery systems in the real world. Diabetes Technol Ther. https://doi.org/10.1089/dia.2020.0031

30. Streisand R, Monaghan M (2014) Young children with type 1 diabetes: challenges, research, and future directions. Curr Diab Rep 14(9):520. https://doi.org/10.1007/s11892-014-0520-2

31. Seckold R, Howley P, King BR et al (2019) Dietary intake and eating patterns of young children with type 1 diabetes achieving glycemic targets. BMJ Open Diabetes Res Care 7(1):e000663. https://doi.org/10.1136/bmjdrc-2019-000663

32. Wang J, Geng L (2019) Effects of socioeconomic status on physical and psychological health: lifestyle as a mediator. Int J Environ Res Public Health 16(2):281. https://doi.org/10.3390/ijerph1602 0281

33. Nicola M, Alsafi Z, Sohrabi C et al (2020) The socio-economic implications of the coronavirus pandemic (COVID-19): a review. Int J Surg 78:185-193. https://doi.org/10.1016/j.ijsu.2020.04.018

Publisher's Note Springer Nature remains neutral with regard to jurisdictional claims in published maps and institutional affiliations. 